\title{
Nonlinear Finite Element Modelling of Railway Turnout System considering Bearer/Sleeper-Ballast Interaction
}

\author{
James Sae Siew, ${ }^{1,2}$ Olivia Mirza, ${ }^{2}$ and Sakdirat Kaewunruen ${ }^{3}$ \\ ${ }^{1}$ JKW Engineering, Penrith, NSW 2057, Australia \\ ${ }^{2}$ School of Civil Engineering, University of Western Sydney, Penrith, NSW 2057, Australia \\ ${ }^{3}$ Birmingham Centre for Railway Research and Education, School of Civil Engineering, \\ The University of Birmingham, Edgbaston, Birmingham B15 2TT, UK \\ Correspondence should be addressed to Sakdirat Kaewunruen; sakdirat@hotmail.com
}

Received 11 September 2014; Accepted 17 February 2015

Academic Editor: Lucio Nobile

Copyright $\odot 2015$ James Sae Siew et al. This is an open access article distributed under the Creative Commons Attribution License, which permits unrestricted use, distribution, and reproduction in any medium, provided the original work is properly cited.

Rail turnouts are built to enable flexibility in the rail network as they allow for vehicles to switch between various tracks, therefore maximizing the utilisation of existing rail infrastructure. In general, railway turnouts are a safety-critical and expensive feature to a rail system as they suffer aggressive operational loads, in comparison to a plain rail track, and thus require frequent monitoring and maintenance. In practice, great consideration is given to the dynamic interaction between the turnouts components as a failed component may have adverse effects on the performance of neighbouring components. This paper presents a nonlinear 3D finite element (FE) model, taking into account the nonlinearities of materials, in order to evaluate the interaction and behaviour of turnout components. Using ABAQUS, the finite element model was developed to simulate standard concrete bearers with $60 \mathrm{~kg} / \mathrm{m}$ rail and with a tangential turnout radius of $250 \mathrm{~m}$. The turnout structure is supported by a ballast layer, which is represented by a nonlinearly deformable tensionless solid. The numerical studies firstly demonstrate the importance of load transfer mechanisms in the failure modes of the turnout components. The outcome will lead to a better design and maintenance of railway turnouts, improving public safety and operational reliability.

\section{Introduction}

Rail operators are considerably demanded by the public and other stakeholders to be more efficient than ever. As a result, the maximisation of utilisation and flexibility of rail network is one of the key strategies in rail asset management. A railway turnout is a critical part of the railway where tracks cross over one another at an angle to divert a train from the original track. It allows for train vehicles to cross over or switch between various tracks and in turn maximising the utility of tracks and assets. Its main components include rails, switches, crossings, steel plates, bearers, ballast, and subgrade (as shown in Figure 1). The rail turnouts are an essential part of a rail system but, at the same time, they are a costly feature to a rail system as they suffer adverse operational loads, in comparison to a plain rail track and require frequent maintenance. Due to the particular geometry of wheel-rail contact and sudden variation of track flexibility, severe impact loads may occur during train passage over the turnout. Turnout components are subjected to general wear, rolling contact fatigue, and accumulated irreversible (plastic) deformations $[1,2]$.

Railway track structures experience static, dynamic, and often impact loading conditions due to wheel/rail interactions associated with the abnormalities in either a wheel or a rail over their life cycle $[3,4]$. Specially at turnouts crossing, the wheel-rail interaction at the transfer zone often causes detrimental impact forces and excessive dynamic actions [57]. Many studies showed that it is very likely that railroad turnout bearers or crossties could be subjected to severe impact loads, resulting in a rapid deterioration in terms of structural integrity and durability, track settlement, and ride comfort [8-10]. Traditional turnouts generally impart high impact forces on to structural members because of their blunt geometry and the gaps between mechanical connections between closure rails and switch rails (i.e., heel-block joints). 


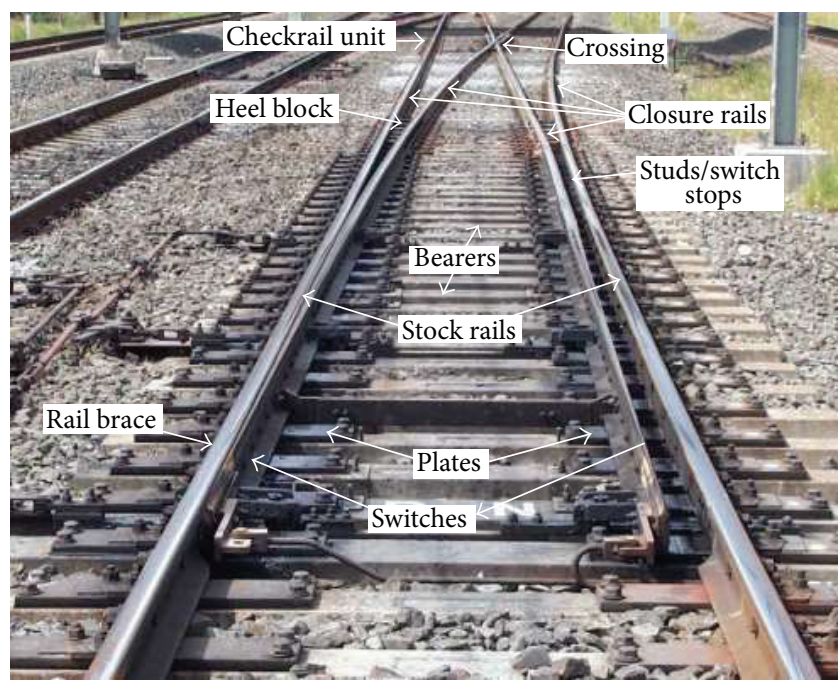

FIgURE 1: Typical components of a railway turnout.

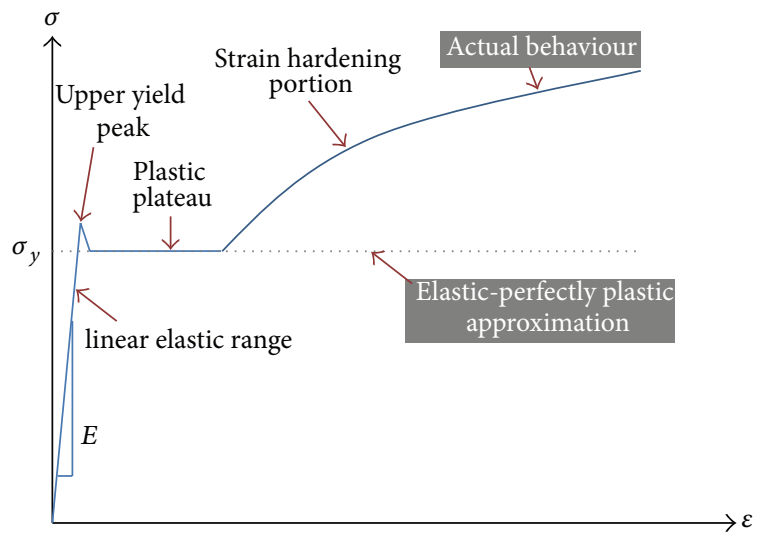

FIGURE 2: Stress-strain relationship of structural steel [30].

Although a new smoother method of geometrical analysis and tangential design to improve wheel/rail navigations has been adopted for turnouts, the transfer zone at a crossing nose in any complex turnout system still generates high-intensity impact forces to turnout components. Generally, the turnout bearers for supporting points and crossing structures were designed using the beam on elastic foundation analysis or 2D FE grillage modelling $[11,12]$. Kaewunruen $[13,14]$ indicated from recent work that some additional factors were often neglected from the grillage analyses, although they must be taken into account in the design process, including

(i) extra length of turnout bearers in comparison with standard sleepers,

(ii) centrifugal forces through curved pairs of rails,

(iii) forces and bending moments induced from points motors and other signaling equipment,

(iv) impact forces induced by wheel-rail interaction,

(v) mechanical rail joints.

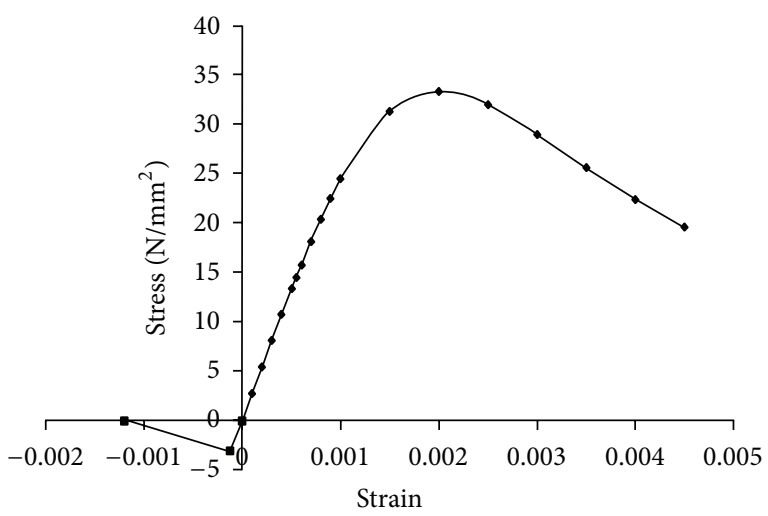

FIGURE 3: Stress-strain relationship of concrete [30].

On this ground, this numerical study was initiated by a recent number of reportedly broken concrete bearers on a mixed-traffic line in New South Wales (NSW), Australia. Due to the complexity of the loadings and damage modes in railway turnouts, this study aims to establish a threedimensional (3D) finite-element (FE) model. The 3D FE model adopts an elastoplastic region of bending and shear deformation of materials. The 3D FE model was developed based upon a common tangential turnout used in Australia. This study indicates that the crossing panel is where turnout bearers experience the greatest bending moment and shear force and it provides the critical force envelopes for design improvement of turnout bearers.

\section{Finite Element (FE) Modelling}

Railway turnout systems have generally been analysed using a grillage beam method (Manalo et al., 2010) [12, 15]. Although the simplification is useful, such a method cannot adequately assist in the failure analyses of turnout components. In some cases, the results using the grillage beam method seem to have discrepancies with the field observations where the maximum bending and shear forces were evident within the crossing panel [16-19]. A number of researches have been conducted to locate the critical section within a turnout, and many of which conclude that the critical section is located specifically at the crossing panel [20-23].

This paper presents a nonlinear 3D FE analysis using ABAQUS considering the whole turnout, which comprises bearers, rail, guard rails, crossing nose, rail pads, baseplates, and guardrail support plates. The benefits of modelling in 3D space are to incorporate the effects of the neighbouring bearers and to take into consideration the longitudinal forces of the continual rail. The boundary conditions of the central $3 \mathrm{D}$ model can be simulated enabling vibrations to radiate beyond the model [24].

2.1. Wheel/Rail Interface (W-R): A Practical Implication. In general, the surface conditions of the wheel and rail play a critical role in the W-R contact force, in addition to geometric irregularities, train speeds, and type of track structure. The large contact force will accelerate the deterioration rate of 


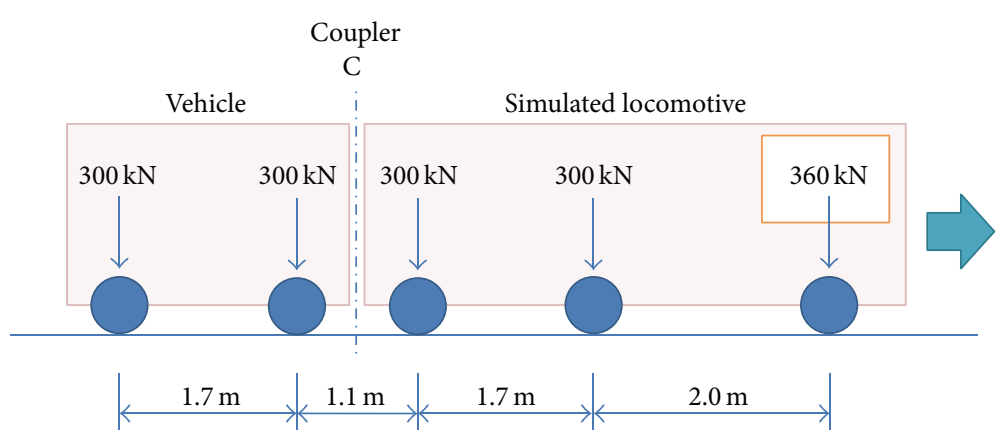

(a) 300LA load case
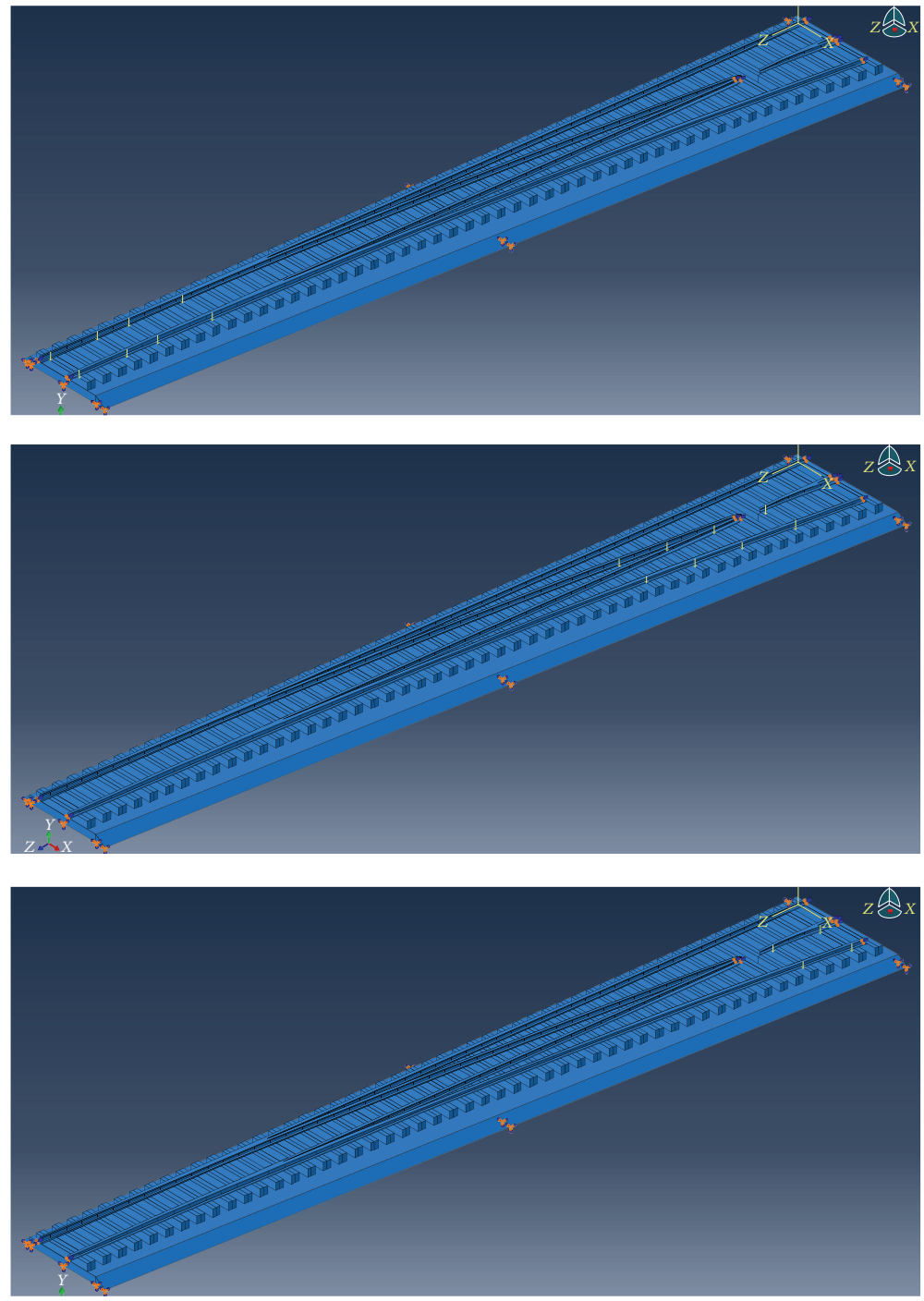

(b) Load steps: 300LA coupled locomotive design loading on turnout; (top) load step 2, (middle) load step 36, and (bottom) load step 48

FIgURE 4: Railway traffic loads-axle loads.

the turnout crossing. Sun et al. [25] provided an insight into the potential sites for impact and fatigue damage as the train wheel traverses through the nose of the crossing. Firstly, the wing rail fatigue damage is caused by contact from the far side of wheel. Secondly, the transition of the wheel between the wing rail and nose causes a dipping movement. This is due to the tracking on the wing rail to an upward motion on the ramp of the nose resulting in fatigue damage. Greater contact stress can be seen due to the acute contact area in the crossing nose. The British Railways Board [26] 


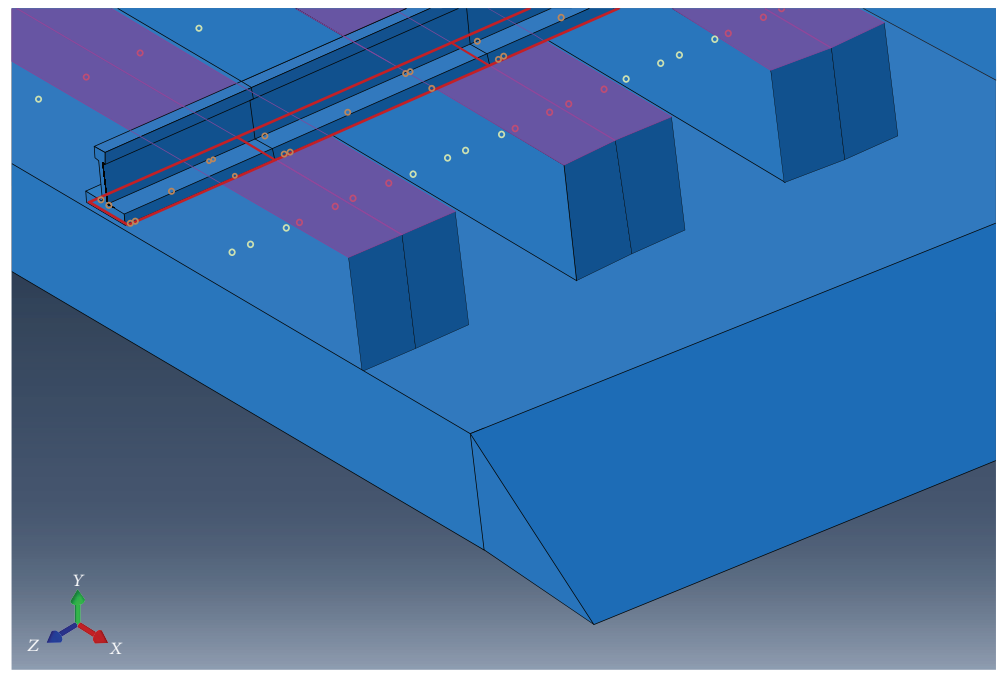

(a) Tie constraint between rail and bearer

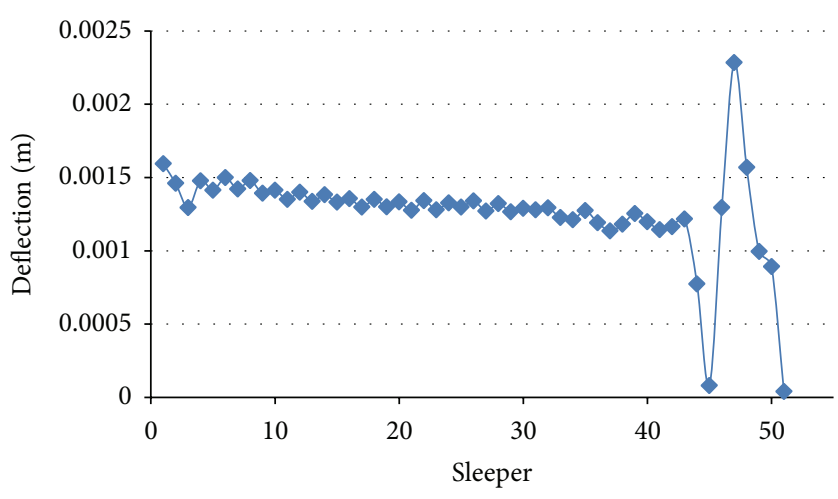

(b) Maximum recorded deflection at each bearer (midpoint)

FIGURE 5: Midpoint deflections of each bearer along the turnout.

expressed that the permissible track forces in a low frequency range (or called $P_{2}$ forces) for railway vehicles negotiating a discontinuity in rail profile do not exceed $322 \mathrm{kN}$ whilst operating at their maximum design speed. In Australia, the $P_{2}$ force is limited to $290 \mathrm{kN}$ for locomotives on very good track structure or otherwise must be less than $230 \mathrm{kN}$. The $P_{2}$ force is calculated using the following formula:

$$
P_{2}=Q+\left(A_{z} \cdot V_{m} \cdot M \cdot C \cdot K\right),
$$

where

$$
\begin{aligned}
M & =\left[\frac{M_{v}}{M_{v}+M_{z}}\right]^{0.5}, \\
C & =\left[\frac{\pi \cdot C_{z}}{4\left[K_{z}\left(M_{v}+M_{z}\right)\right]^{0.5}}\right], \\
K & =\left(K_{z} \cdot M_{v}\right)^{0.5},
\end{aligned}
$$

the lesser of

$$
\begin{aligned}
Q & =0.13 D \times 10^{3} \\
\text { or } Q & =125 \times 10^{3},
\end{aligned}
$$

where $D$ is the wheel diameter ( $\mathrm{mm}), Q$ is the maximum static wheel load $(\mathrm{N}), V_{m}$ is the maximum normal operating speed $(\mathrm{m} / \mathrm{s}), M_{v}$ is the effective vertical unsprung mass per wheel $(\mathrm{kg}), A_{z}$ is total dip angle of vertical ramp discontinuity (taken as $0.02 \mathrm{rad}$ ), $M_{z}$ is taken to be $245 \mathrm{~kg}$ as the effective vertical rail mass per wheel, $C_{z}$ is taken to be $55.4 \times 10^{3} \mathrm{~N} / \mathrm{m}$ as the effective vertical rail damping rate per wheel, and $K_{z}$ is taken to be as $62 \times 10^{6} \mathrm{~N} / \mathrm{m}$ as the effective vertical rail stiffness per wheel.

In addition, lateral resistance is usually designed to reinforce the structural integrity of the rail and turnout. Considerations are only given to lateral force values sustained for distances of 2 metres or more. Unless supported by appropriate technical justification, vehicles attempting to negotiate a lateral ramp discontinuity in track alignment, when travelling on a curve at maximum normal operating 


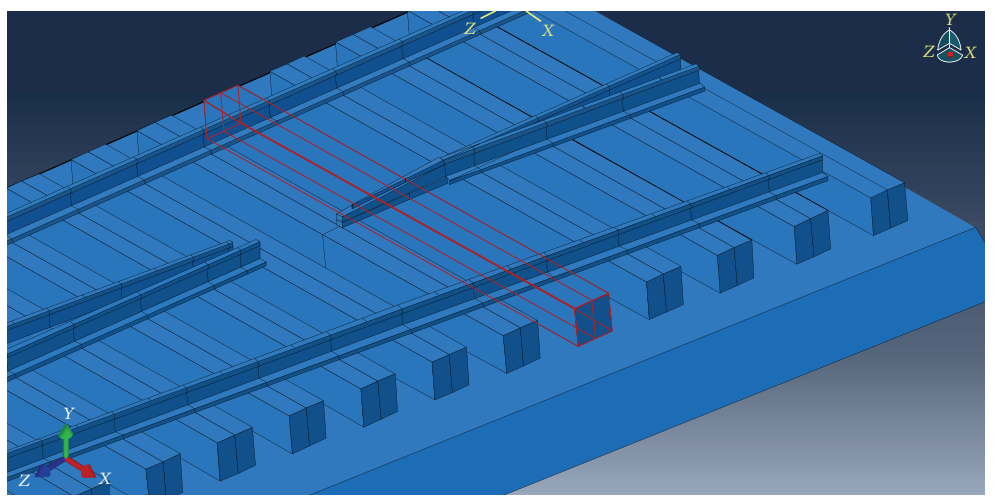

(a) Bearer 47 (red) experiences the greatest deflection

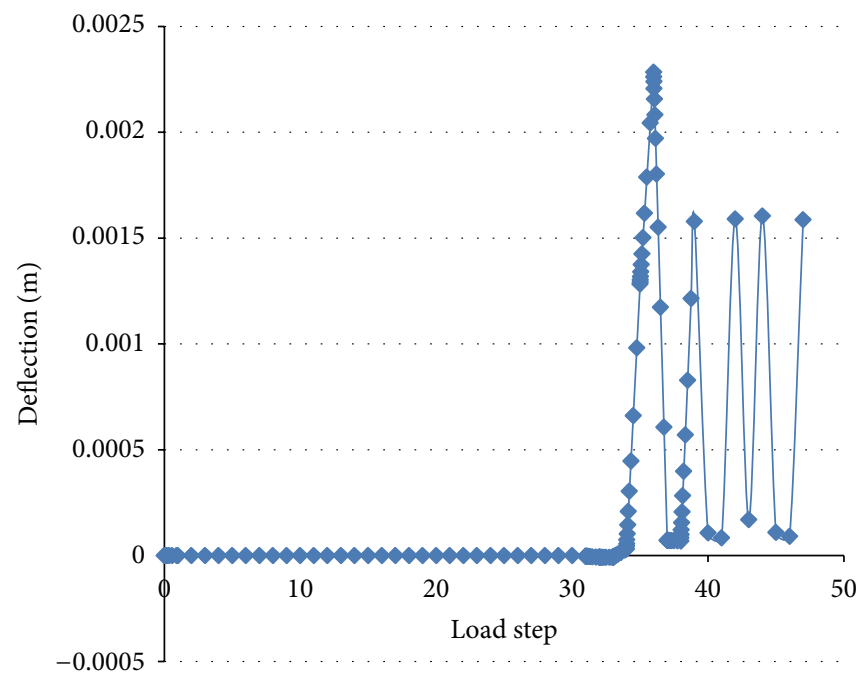

(b) Deflection response of bearer 47 at each load step

FIGURE 6: Displacement envelope of the bearer right underneath the crossing (number 47).

speed and at maximum cant deficiency, without exceeding a total lateral force level per axles of $71 \mathrm{kN}$, should introduce lateral action that can be calculated using the following formula [26]:

$$
Y=W \cdot A_{d}+A_{y} \cdot V_{m}\left[\frac{M_{u}}{M_{u}+M_{y}}\right]^{0.5} \cdot\left[K_{y} \cdot M_{u}\right]^{0.5}
$$

where $Y$ is the lateral force per axle $(\mathrm{N}), W$ is the static axle load $(\mathrm{N}), A_{d}$ is the maximum normal operating cant deficiency angle (rad), $V_{m}$ is the maximum normal operating speed $(\mathrm{m} / \mathrm{s}), M_{u}$ is the effective lateral unsprung mass per axle (kg), $A_{y}$ is taken to be $0.0038 \mathrm{rad}$ which is the angle of lateral ramp discontinuity, $M_{y}$ is taken as $170 \mathrm{~kg}$ and is the effective lateral rail mass per wheel, and $K_{y}$ is taken to be $25 \times 10^{6} \mathrm{~N} / \mathrm{m}$ as the effective lateral rail stiffness per wheel. Based on these formulas, the dynamic forces can be estimated for the design of turnout components.

2.2. Turnout Components. The FE model comprises entirely $3 \mathrm{D}$ deformable solids, straight and curved rail, bearers of varying length, and a ballast layer as the track support. This study focuses on the behaviour of the bearer and ballast; therefore, a suitably accurate rail seat load within a tangential configuration is required for the analysis. Steel rails were modelled in 3D space to account for their cross-sectional properties, the width of the contact patch between the wheel and rail, the width of the rail web, and the width of the rail footing. The rail and switch rail profiles were validated against rail authority's specifications [27-29]. Table 1 shows the engineering properties of turnout structural components. Concrete bearers have been modelled as rectangular blocks with dimensions nominated according to the specifications varying lengths between $2.5 \mathrm{~m}$ to $7.5 \mathrm{~m}$ according to the turnout design.

The elastic modulus of steel rails and crossing is defined by the initial slope of the stress-strain relationship to the extent of the upper yield threshold, as illustrated in Figure 2. For concrete material, it is assumed that its initial compressive stress behaviour is to be linear given that it does not exceed $0.4 f^{\prime}{ }_{c}[30]$. Beyond the linear threshold, nonlinear stress is expressed as a function of strain according to (5). A graphical representation of the stress-strain relationship of concrete is depicted in Figure 3. Consider

$$
f_{c}^{\prime}
$$


TABLE 1: Design properties of materials.

\begin{tabular}{lccc}
\hline Materials & Elastic modulus $(\mathrm{MPa})$ & Compressive strength $(\mathrm{MPa})$ & Tensile strength $(\mathrm{MPa})$ \\
\hline Concrete & 38,000 & $36-55$ & $4.0-6.30$ \\
Prestressing tendon & 200,000 & - & 1,700 \\
Steel rails & 205,000 & - & - \\
\hline
\end{tabular}

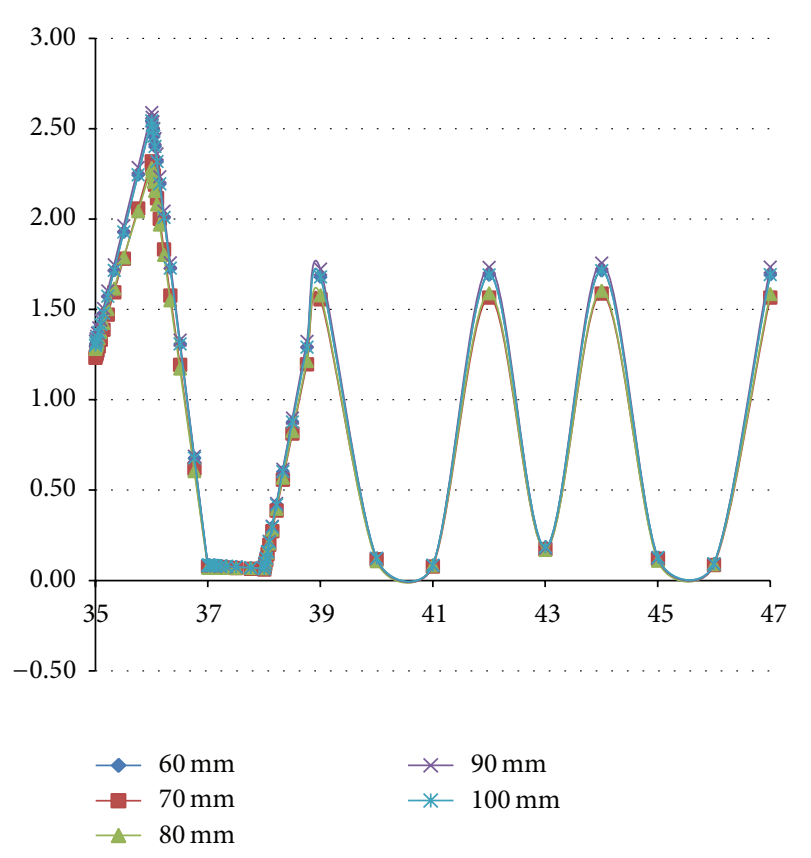

FIGURE 7: Effect of mesh sizes on the deflection of the bearer underneath the crossing nose (number 47).

where

$$
\begin{aligned}
\gamma & =\left|\frac{f^{\prime}{ }_{c}}{32.4}\right|^{3}+1.55, \\
\varepsilon_{c}^{\prime} & =0.002 .
\end{aligned}
$$

The ballast layer is simulated as a hardening-soil (HS) model [31]. This method is an advanced method in analysing the mechanical behaviour in soil as it considers the plasticity theory, along with the effect of viscosity on the shear strain and a yield cap. In this study, the evaluation takes upon the approach of simplifying the ballasted track support using elastoplastic solid elements [22,32]. A track support modulus of $50 \mathrm{MPa}$ is adopted to comply with the design requirements and field data $[27,28]$.

2.3. Constraints and Boundary Conditions. A sensitivity analysis has been undertaken for mesh sizes for each rail component. As the mesh sizes and the material densities are different between the two tied objects, a tie constraint is generated to allow for ABAQUS to automatically optimise and refine the interface mesh. Tie constraints are applied to the rail and the concrete bearers to represent the rail fasteners. Instead of frictional interaction and the effect of submersed bearers in a ballast layer, the bearers are tied onto the underlying ballast layer to greatly reduce computational effort. As all members are tied, translational and rotational degrees of freedom will be distributed throughout. All tie constraints were taken as surface to surface, as opposed to a simplified node to surface, as this allowed for uniform distribution between the tied components. The interface between bearer or sleeper and ballast has been treated with contact surface elements where the bearers can lift freely as ballast is modelled using tensionless solid elements [24].

A fixed boundary condition is applied to the bottom most surface of the subballast to idealise the substructure and a symmetrical constraint is applied to the ends of the rail to idealise a continuous rail within the relevant plane, in this case the $z$-axis. The bearers are attached to other members with boundary constraints, and they can deform freely with the ballast bed. Note that this model is currently limited to the investigations of ballast layer up to track structures. To evaluate soil formation behaviour, the model can be further extended to accommodate contact support conditions and soil foundation layers.

2.4. Load Conditions. Loading configuration is in accordance with Standards Australia [33]. The design loads are depicted in Figure 4(a), which simulate the worst case loading configuration that can be exerted onto a rail track. The FE model predicts the behaviour of the turnout by considering multiwheel impacts, which would simulate in-service and cyclic loading and have been adapted as a set of concentrated loads negotiating the turnout to represent a moving coupled locomotive (in order to form the worst case scenario for the design). The coupled locomotive is then simulated with four $300 \mathrm{kN}$ axle loads and a single $360 \mathrm{kN}$ axle load 2 meters ahead of the group.

The above load set is applied to the model at $600 \mathrm{~mm}$ increment initially to coincide with turnout bearer spacing, or referred to hereafter as load sets. A total of 48 load steps (including model initiation) are modelled to generate the overall movement of the locomotive negotiating the turnout. When approaching the crossings, the load step is later set at $50 \mathrm{~mm}$ increment. Figure 4(b) illustrates loading configurations for particular steps.

2.5. Validation. The numerical model was previously calibrated using the field measurement data $[13,14,34,35]$. Along with an accurate resultant deflection, the time required to compute the analysis is also significant in selecting an optimum mesh size. The typical aggregate size of ballast in practice is anywhere between $13 \mathrm{~mm}$ and $65 \mathrm{~mm}$. An initial analysis is carried out to determine the maximum 


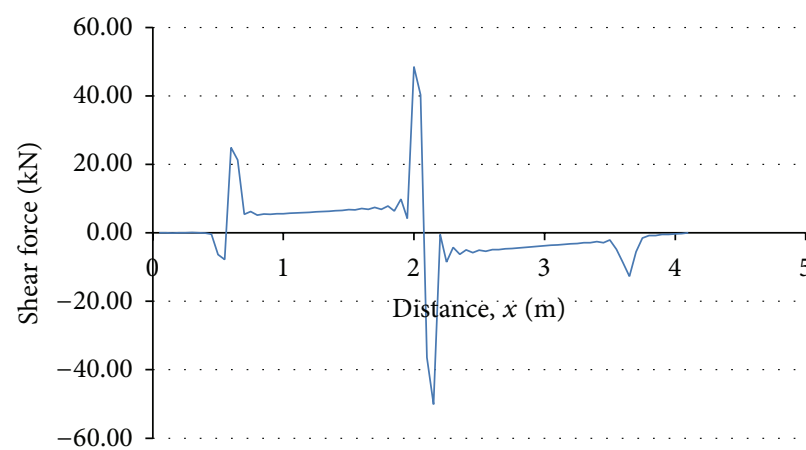

(a) Shear force envelope of bearer 47 upon wheel impact

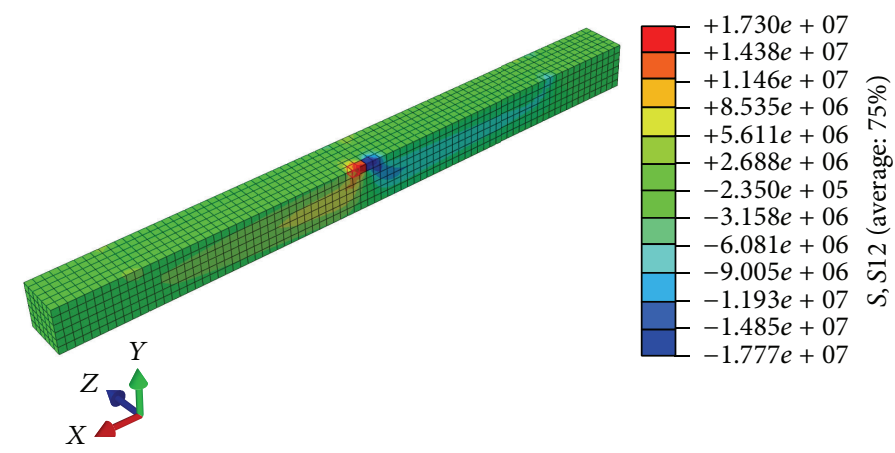

(b) Shear stress distribution of bearer 47 (under load step 36)

FIGURE 8: Shear force envelope of the bearers upon wheel impact.

TABLE 2: Resultant deflection of sleeper 47 and computational time with varying ballast mesh size.

\begin{tabular}{lcc}
\hline Mesh size $(\mathrm{mm})$ & Deflection $(\mathrm{mm})$ & Computational time $(\mathrm{s})$ \\
\hline $60 \times 60$ & 2.54 & 24,784 \\
$70 \times 70$ & 2.32 & 12,638 \\
$80 \times 80$ & 2.28 & 10,824 \\
$90 \times 90$ & 2.59 & 5,655 \\
$100 \times 100$ & 2.54 & 5,547 \\
\hline
\end{tabular}

deflection under the said design train loading. Figure 5 shows the maximum vertical deflection, taken at the midpoint of each bearer, with a single pass of the coupled locomotive load. The deflection response is presented graphically in Figure 6. It can be seen that the bearer does not undergo any translations up until the 35th load step. This is an important step in dramatically reducing the computational time required to analyse the model with different mesh sizes. As we have located the critical bearer in the preliminary test, it is advantageous to exclude all previous steps between the initial and 34th step from the analysis in determining optimum mesh size as this reduces the computational time by almost $80 \%$. Table 2 lists the maximum deflection of the chosen bearer under train loading according to varied mesh sizes [35]. It can be seen from the results above that although the $60 \mathrm{~mm}$ and $100 \mathrm{~mm}$ meshes yield similar precision and accuracy of the numerical results, the former takes almost 4.5 times the amount of time to compute compared to the latter. To maximise the computing time efficiency, the $100 \mathrm{~mm} \times$ $100 \mathrm{~mm}$ mesh is chosen for this study.

\section{Results and Discussion}

In practice, frequent maintenance of supporting bearers and fastening systems can often be observed in the field even though those components have been designed in accordance with engineering standards. This study has therefore investigated such an important issue. It is found that the bearers, which undergo the greatest deflection of a coupled locomotive pass, are the bearers underneath the crossing nose (maximum at bearer number 47 ). The sensitivity analysis illustrates the maximum deflection in all bearers with the passing of a moving couple train load, 300LA [33]. From the sensitivity analysis, it can be seen from Figure 7 that the bearer directly underneath the crossing (number 47) experiences the greatest deflection, with a resultant of $2.54 \mathrm{~mm}$. The sharp spike in deflection clearly defines the moment at which each wheel axle impacts the above rail, in this case the crossing nose. Any lateral sliding due to such vertical load action cannot be observed.

The shear stress response of crossing bearer (number 47) at the most critical loading is illustrated Figure 8. It can be witnessed that the large spike at the midpoint is obviously the point at which the wheel impacts the crossing nose. Note that this shear response has not been considered in the component design since it is often lower than the shear capacity of prestressed concrete bearers. Figure 9 represents both the bending stresses and moment envelopes given in the design specification $[28,29]$ and the bending moment obtained from the FE analysis by using the methodology recommended in the specification. Four reference points are chosen according to the given bending moment envelope, which is gathered from these reference points $0 \mathrm{~m}, 0.5 \mathrm{~m}$ and total length minus $0.5 \mathrm{~m}$ and at the end span. Figure 9(a) illustrates the bending moment envelope for 2.6 to $2.8 \mathrm{~m}$ long turnout bearers. The black line signifies the bending moment envelope which is found in the design specification [29] and the blue line represents the shear envelope obtained from the FE analysis, specifically bearer 21 (the bearer under the closure rails). It can be seen that the computed results do not correlate well with the design allowable actions. However, this may be due to the nature of the loading of the turnout, as the train in this particular instance is often modelled to travel along the diverging, tangential path and the loading should not be expected to be linear or symmetrical, unlike what is depicted in the design specification. Figure 9(b) demonstrates the comparison of a chosen bearer with the suggested design envelope. The crossing bearer (critical bearer number 47) is chosen to validate the data sets and results. As with the former example, the black line represents the bending moment envelope specified in the design standards [28, 29]. The bending moment envelope is intended to be used for turnout bearers between the lengths $2.8 \mathrm{~m}$ and $5.2 \mathrm{~m}$. Again, 


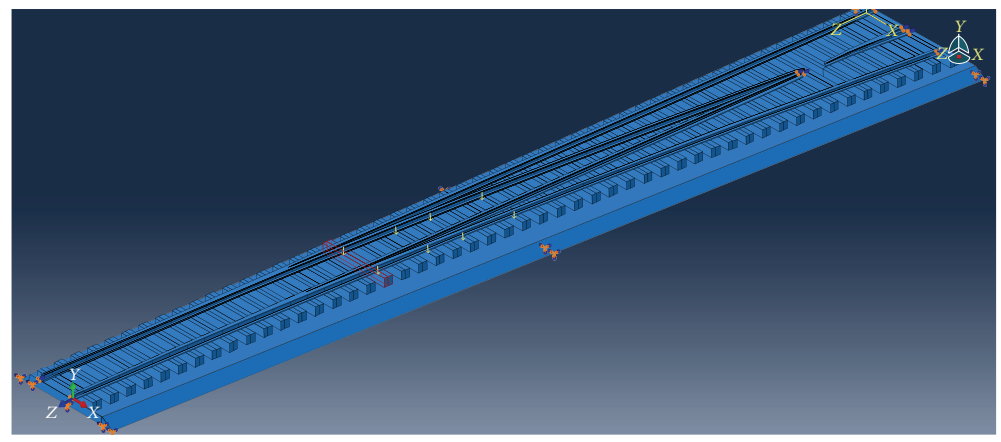

(a) Bearer 21 (red) in relation to load step 18 (yellow)
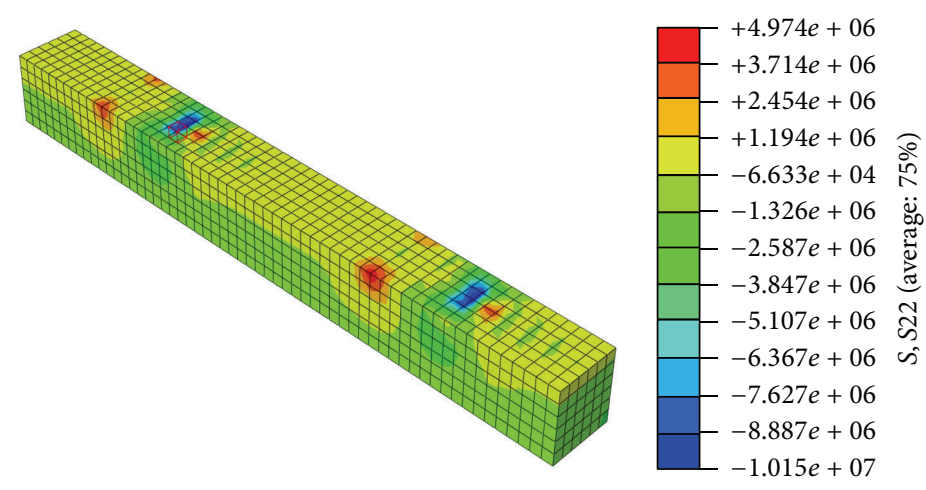<smiles>[Y]C=C(C[Z])C[Y]</smiles>

(b) Bending stress of bearer 21 under load step 18

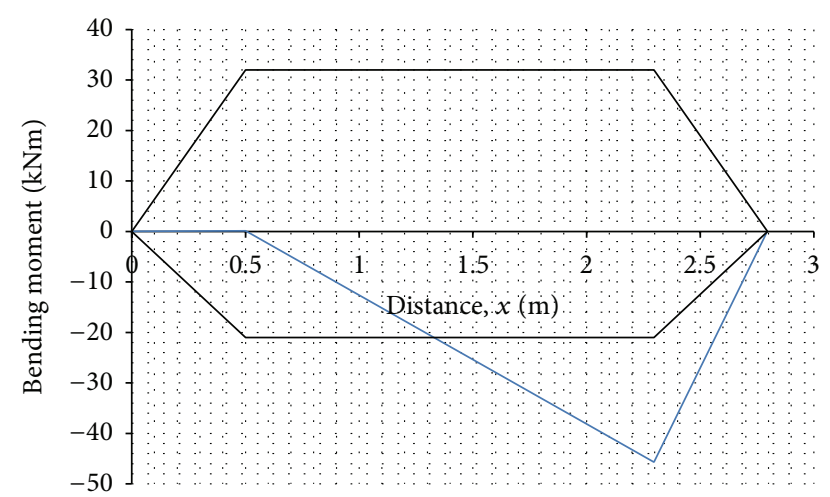

(c) Bending moment envelope of bearer 21 with computed values (blue) against specifications (black)

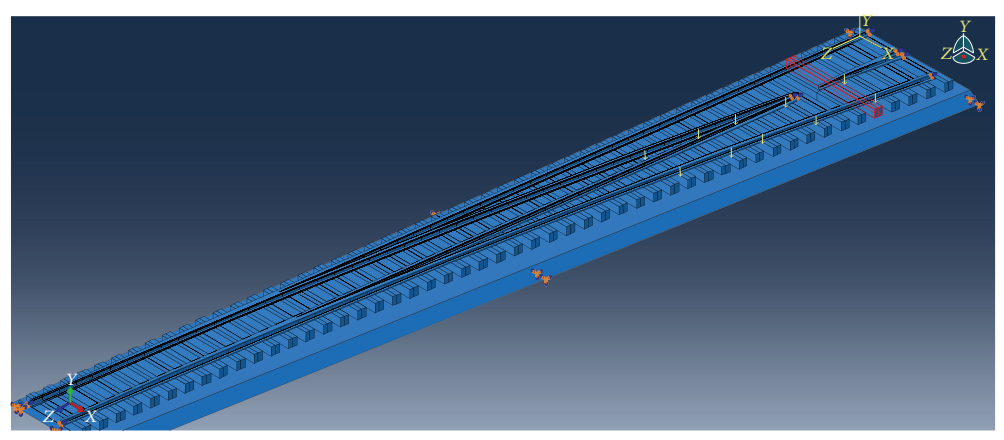

(d) Bearer 47 (red) in relation to load step 36 (yellow)

FIGURE 9: Continued. 


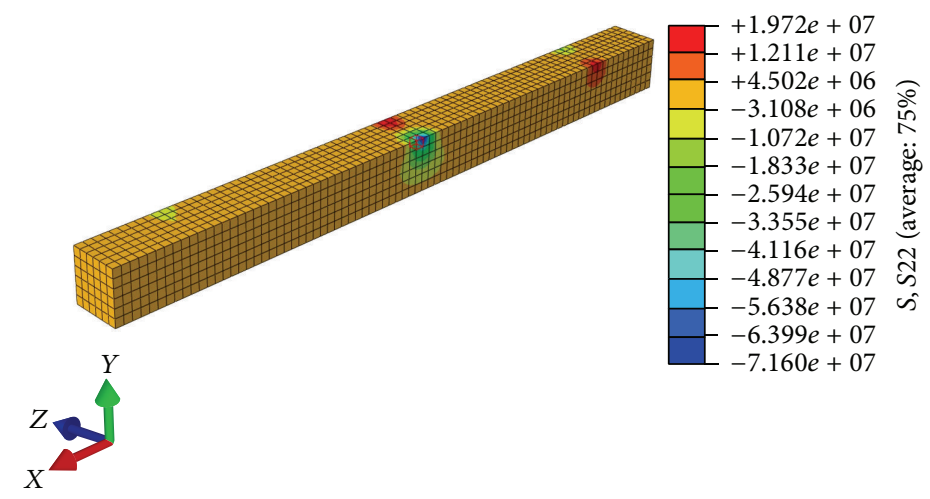

(e) Bending stress of bearer 47 under load step 36

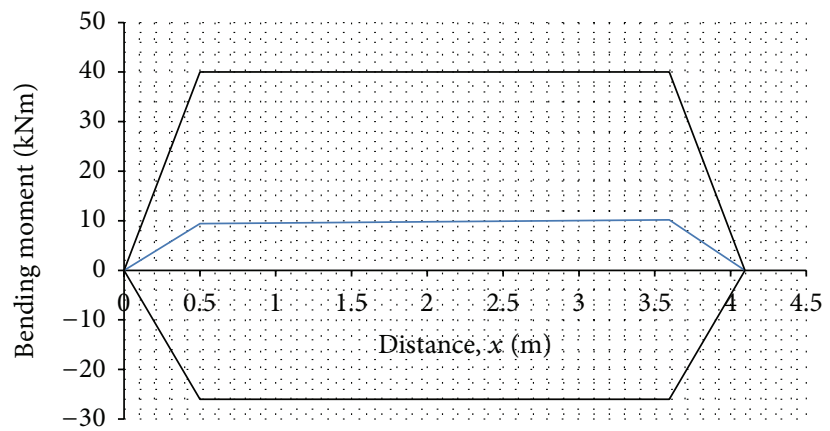

(f) Bending moment envelope of bearer 47 with computed values (blue) against specifications (black)

FiguRE 9: Bending stresses and moment envelopes of turnout bearers.

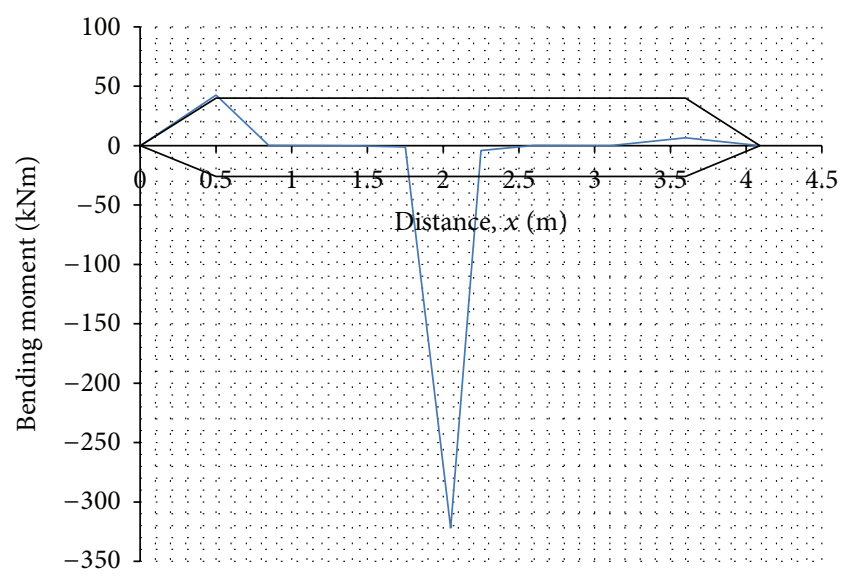

FIGURE 10: Bending moment envelope of FE model, bearer 47 (blue), and specifications (black).

the FE analysis has yielded resultant moments from the reference points.

Due to the unchanging response of the modelled result and the fact that the bearers under the crossings experience critical loading, it is believed that the moment envelope overlooks the adverse loading configurations of a turnout system and, instead, idealises the moment response to that of straight rail. Figures 10 and 11 display the comparative bending moment envelopes for the bearer at crossing (number

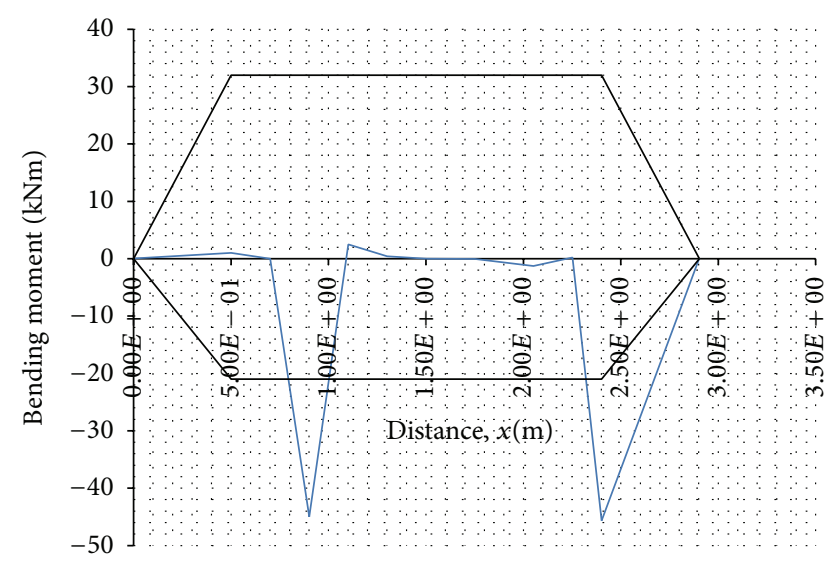

FIGURE 11: Bending moment envelope of bearer 21. Bending moment of FE model, bearer 21 (blue), and specifications (black).

47) and the bearer at closure rail (number 21). Retaining the same convention as earlier envelopes, the blue line signifies the FE analysis. There is an obvious spike approximately at the midpoint of the bearer span. It is logical to assume that the impact of the wheel onto the crossing nose will greatly influence the shear and bending envelope. Although there may be a huge deviation between the specified value and the simulated result, it should be noted that the envelope within SPC 233 [29] shows no deviation nor increased loading within that particular location whatsoever. 
It is concerning the fact that the maximum bending moment simulated, being $322 \mathrm{kNm}$, is greater than that specified by about $800 \%$. Also that no change in loading condition or material property has been changed is noteworthy; yet, by involving a greater number of points in which to create an accurate stress diagram, the loading may be allowed to deviate so greatly. As the increase in bending moment is concentrated within the midspan, it can be deduced that the midspan could become more susceptible to permanent deformations and cracking that was not designed to not be designed to accommodate for the adverse loading.

The resultant bending diagram depicted in Figure 11 shows the much more comprehensive bending envelope in comparison to those given within specifications. The envelope given in the specifications depicts a much more linear approach to bending moment design, and it is speculated that the diverse geometry of a rail turnout has been overlooked altogether. The significance of the bending moment envelope obtained for the bearer under closure rail (number 21) is that not only does the larger bending moment occur at the point of wheel impact, but it also has the characteristic of uneven loading, which is precisely when the train is diverting into the tangential track.

\section{Conclusions}

This paper firstly presents a development of threedimensional finite element model of a tangential turnout system for an investigation into the failure modes that were arisen from the field observations and measurements on a mixed traffic rail line whereas broken concrete bearers and loose fasteners were reported routinely. A 3D FE model has been established and validated for the analysis of a complete turnout system. The primary objective of this study is to determine the critical location, be able to realise the critical deflection, and validate shear force and bending moment envelopes of a turnout system. To address this, ABAQUS has been employed to carry out all modelling and postprocessing of a complete 3D turnout. From the detailed analysis, turnout bearers right underneath crossing panel experience the highest load actions, resulting in the largest deformations. It is also found that the turnout sleeper or bearer underneath the closure rails or where there is a change in rail curvature is subjected to a high level of vertical loading, sometimes exceeding its design load limits. These results are of significant importance to rail engineers and track designers, in order to establish a safer and more reliable turnout system. Future work will evaluate the effects of ballast voids and pockets on the dynamic behaviour and lateral sliding of turnout systems.

\section{Conflict of Interests}

The authors declare that there is no conflict of interests regarding the publication of this paper.

\section{Acknowledgments}

The authors are grateful to University of Western Sydney and RailCorp for the support throughout this study. Also, the last author wishes to thank Australian Government for his Endeavour Executive Fellowships at Massachusetts Institute of Technology, Harvard University, and Chalmers University of Technology.

\section{References}

[1] E. Kassa and J. C. O. Nielsen, "Dynamic interaction between train and railway turnout: full-scale field test and validation of simulation models," Vehicle System Dynamics, vol. 46, no. 1, pp. 521-534, 2008.

[2] S. Kaewunruen and A. M. Remennikov, "On the residual energy toughness of prestressed concrete sleepers in railway track structures subjected to repeated impact loads," Electronic Journal of Structural Engineering, vol. 13, no. 1, pp. 31-47, 2013.

[3] A. M. Remennikov and S. Kaewunruen, "A review of loading conditions for railway track structures due to train and track vertical interaction," Structural Control and Health Monitoring, vol. 15, no. 2, pp. 207-234, 2008.

[4] B. A. Pålsson, "Optimisation of railway crossing geometry considering a representative set of wheel profiles," Vehicle System Dynamics, vol. 53, no. 2, pp. 274-301, 2015.

[5] S. Kaewunruen and A. M. Remennikov, "Nonlinear transient analysis of a railway concrete sleeper in a track system," International Journal of Structural Stability and Dynamics, vol. 8, no. 3, pp. 505-520, 2008.

[6] S. Kaewunruen and A. M. Remennikov, "Progressive impact behaviours of prestressed concrete sleepers in railway track environments," Engineering Structures, vol. 31, no. 10, pp. 2460 2473, 2009.

[7] S. Kaewunruen and A. M. Remennikov, "Dynamic crack propagations in prestressed concrete sleepers in railway track systems subjected to severe impact loads," Journal of Structural Engineering, vol. 136, no. 6, pp. 749-754, 2010.

[8] C. Esveld, Modern Railway Track, MRT Press, Amsterdam, The Netherlands, 2001.

[9] S. Kaewunruen, Experimental and numerical studies for evaluating dynamic behaviour of prestressed concrete sleepers subject to severe impact loading [Ph.D. thesis], School of Civil, Mining, and Environmental Engineering, University of Wollongong, Wollongong, Australia, 2007.

[10] S. Kaewunruen, A. M. Remennikov, A. Aikawa, and H. Sakai, "Free vibrations of interspersed railway track systems in threedimensional space," Acoustics Australia, vol. 42, no. 1, pp. 20-26, 2014.

[11] S. Iwnicki, Y. Bezin, G. Xie, and E. Kassa, "Advances in vehicletrack interaction tools," Railway Gazette International, vol. 165, pp. 47-49, 51-52, 2009.

[12] A. Manalo, T. Aravinthan, W. Karunasena, and N. Stevens, "Analysis of a typical railway turnout sleeper system using grillage beam analogy," Finite Elements in Analysis \& Design, vol. 48, no. 1, pp. 1376-1391, 2012.

[13] S. Kaewunruen, "Monitoring structural deterioration of railway turnout systems via dynamic wheel/rail interaction," Case Studies in Nondestructive Testing and Evaluation, vol. 1, pp. 1924, 2014. 
[14] S. Kaewunruen, "Monitoring in-service performance of fibrereinforced foamed urethane sleepers/bearers in railway urban turnout systems," Structural Monitoring \& Maintenance, vol. 1, no. 1, pp. 131-157, 2014.

[15] C. Wan, V. L. Markine, and I. Y. Shevtsov, "Analysis of train/turnout vertical interaction using a fast numerical model and validation of that model," Proceedings of the Institution of Mechanical Engineers F, vol. 228, no. 7, pp. 730-743, 2014.

[16] S. Kaewunruen, "Effectiveness of using elastomeric pads to mitigate impact vibration at an urban turnout crossing," in Noise and Vibration Mitigation for Rail Transportation Systems, T. Maeda, P.-E. Gautier, C. E. Hanson, B. Hemsworth, J. T. Nelson, and Burkhard, Eds., pp. 357-365, Springer, Berlin, Germany, 2012.

[17] B. A. Palsson, Optimisation of railway switches and crossings [Ph.D. thesis], Chalmers University of Technology, Gothenburg, Sweden, 2014.

[18] C. T. Rapp, R. G. Kernes, and M. R. Saat, "Overview of issues and research related to special trackwork for shared high-speed-rail passenger and heavy-axle-load freight operations," Proceedings of the Institution of Mechanical Engineers, Part F: Journal of Rail and Rapid Transit, vol. 228, no. 5, pp. 557-565, 2014.

[19] C. Wan, V. L. Markine, and I. Y. Shevtsov, "Optimisation of the elastic track properties of turnout crossings," Proceedings of the Institution of Mechanical Engineers, Part F: Journal of Rail and Rapid Transit, 2014.

[20] E. Kassa and J. C. O. Nielsen, "Dynamic train-turnout interaction in an extended frequency range using a detailed model of track dynamics," Journal of Sound and Vibration, vol. 320, no. 4-5, pp. 893-914, 2009.

[21] M. Wiest, W. Daves, F. D. Fischer, and H. Ossberger, "Deformation and damage of a crossing nose due to wheel passages," Wear, vol. 265, no. 9-10, pp. 1431-1438, 2008.

[22] J. Xiao, F. Zhang, and L. Qian, "Numerical simulation of stress and deformation in a railway crossing," Engineering Failure Analysis, vol. 18, no. 8, pp. 2296-2304, 2011.

[23] R. Müller, J. C. O. Nielsen, B. Nélain, and A. Zemp, "Groundborne vibration mitigation measures for turnouts: state-of-theart and field tests," in Noise and Vibration Mitigation for Rail Transportation Systems, vol. 126 of Notes on Numerical Fluid Mechanics and Multidisciplinary Design, pp. 547-554, Springer, Berlin, Germany, 2015.

[24] Karlsson and Sorensen, ABAQUS/CAE User's Manual: Element, Hibbitt Publication, Pawtucket, RI, USA, 2006.

[25] Y. Q. Sun, C. Cole, and M. McClanachan, "The calculation of wheel impact force due to the interaction between vehicle and a turnout," Proceedings of the Institution of Mechanical Engineers, Part F: Journal of Rail and Rapid Transit, vol. 224, no. 5, pp. 391403, 2010.

[26] U. M. Cherkashin, S. M. Zakharov, and A. E. Semechkin, "An overview of rolling stock and track monitoring systems and guidelines to provide safety of heavy and long train operation in the Russian Railways," Proceedings of the Institution of Mechanical Engineers, Part F: Journal of Rail and Rapid Transit, vol. 223, no. 2, pp. 199-208, 2009.

[27] Rail Corporation of New South Wales, ESC 240. Ballast, Rail Corporation of New South Wales, Sydney, Australia, 2012.

[28] Rail Corporation of New South Wales, ESC 250. Turnouts and Special Trackwork, Rail Corporation of New South Wales, 2012.

[29] Rail Corporation of New South Wales, SPC 233-Concrete Turnout Bearers, Rail Corporation of New South Wales, 2012.
[30] O. Mirza and B. Uy, "Behaviour of headed stud shear connectors for composite steel-concrete beams at elevated temperatures," Journal of Constructional Steel Research, vol. 65, no. 3, pp. 662674, 2009.

[31] B. Indraratna and S. Nimbalkar, "Implications of ballast breakage on ballasted railway track based on numerical modeling," in Proceedings of the 13th International Conference of the International Association for Computer Methods and Advances in Geomechanics (IACMAG '11), pp. 1085-1092, May 2011.

[32] L. Montalbán Domingo, C. Zamorano Martín, C. Palenzuela Avilés, and J. I. Real Herráiz, "Analysis of the influence of cracked sleepers under static loading on ballasted railway tracks," The Scientific World Journal, vol. 2014, Article ID 363547, 10 pages, 2014.

[33] Standards Australia, AS 5100.2. Bridge Design-Design Loads, Standards Australia, 2004.

[34] S. Kaewunruen, "Discussion of 'mitigation of ground vibration generated by high-speed trains on saturated poroelastic ground with under-sleeper pads' by Zhigang Cao, Yuanqiang Cai, and Jie Han," Journal of Transportation Engineering, vol. 141, no. 1, Article ID 07014003, 2015.

[35] J. Sae Siew, O. Mirza, and S. Kaewunruen, "Torsional effect on track support structures of rail turnouts crossing impact," ASCE Journal of Transportation Engineering. Submitted. 

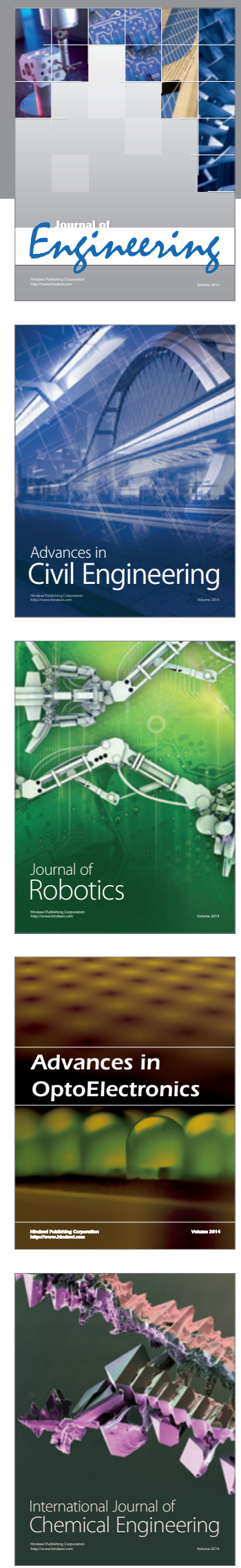

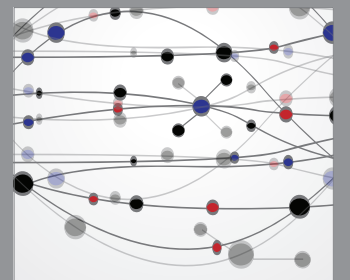

The Scientific World Journal
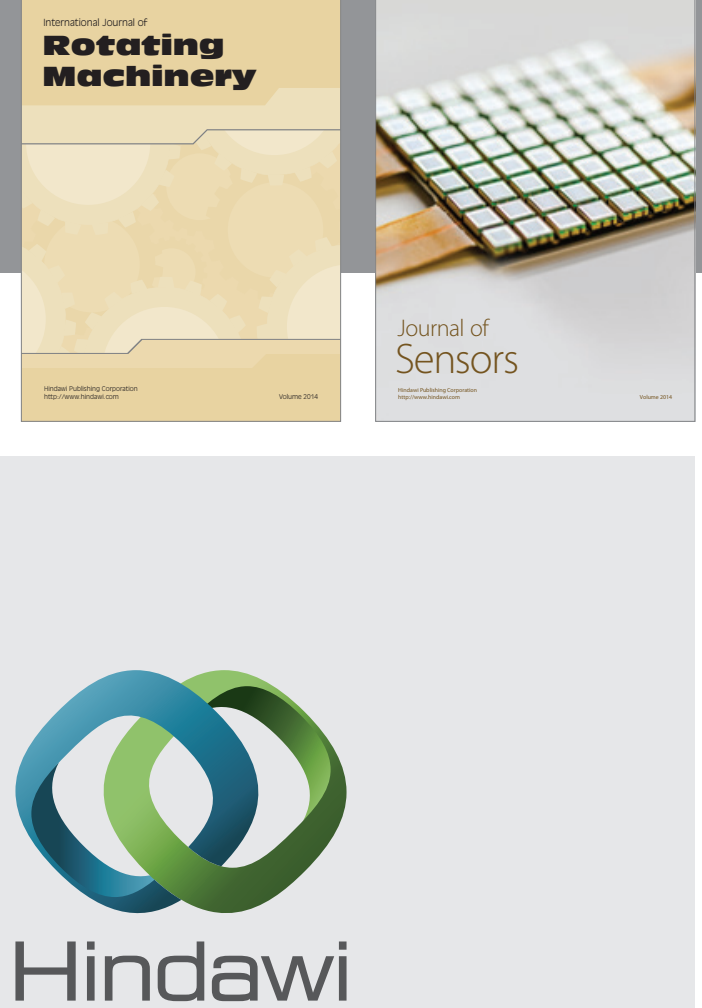

Submit your manuscripts at http://www.hindawi.com
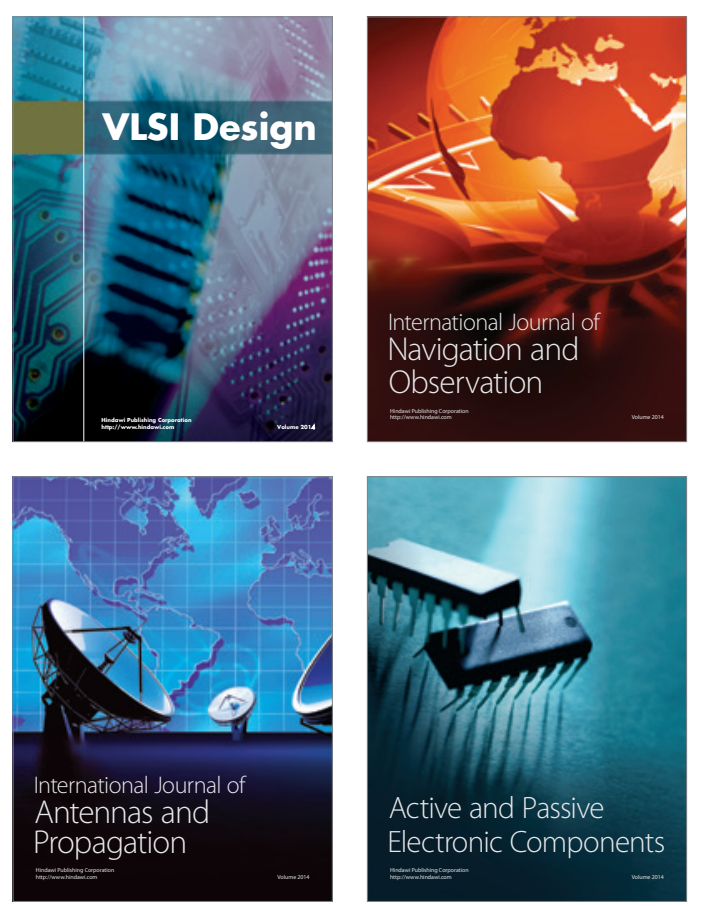
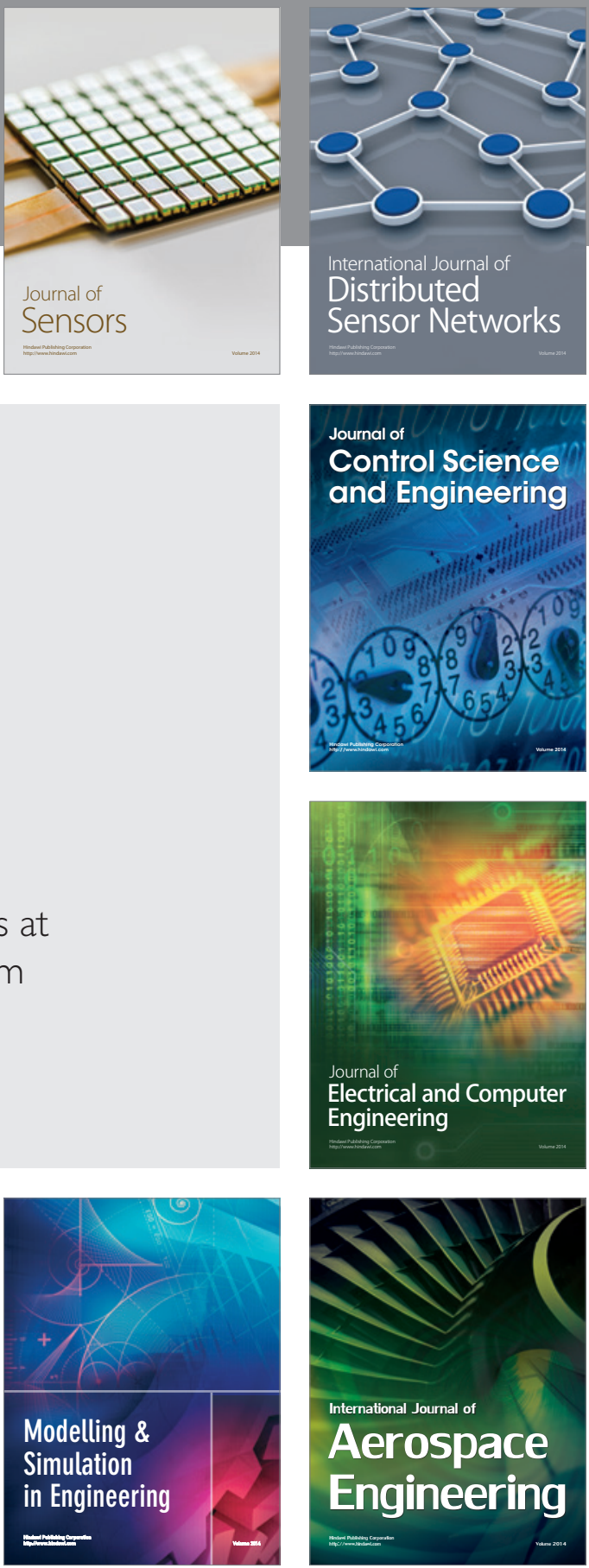

Journal of

Control Science

and Engineering
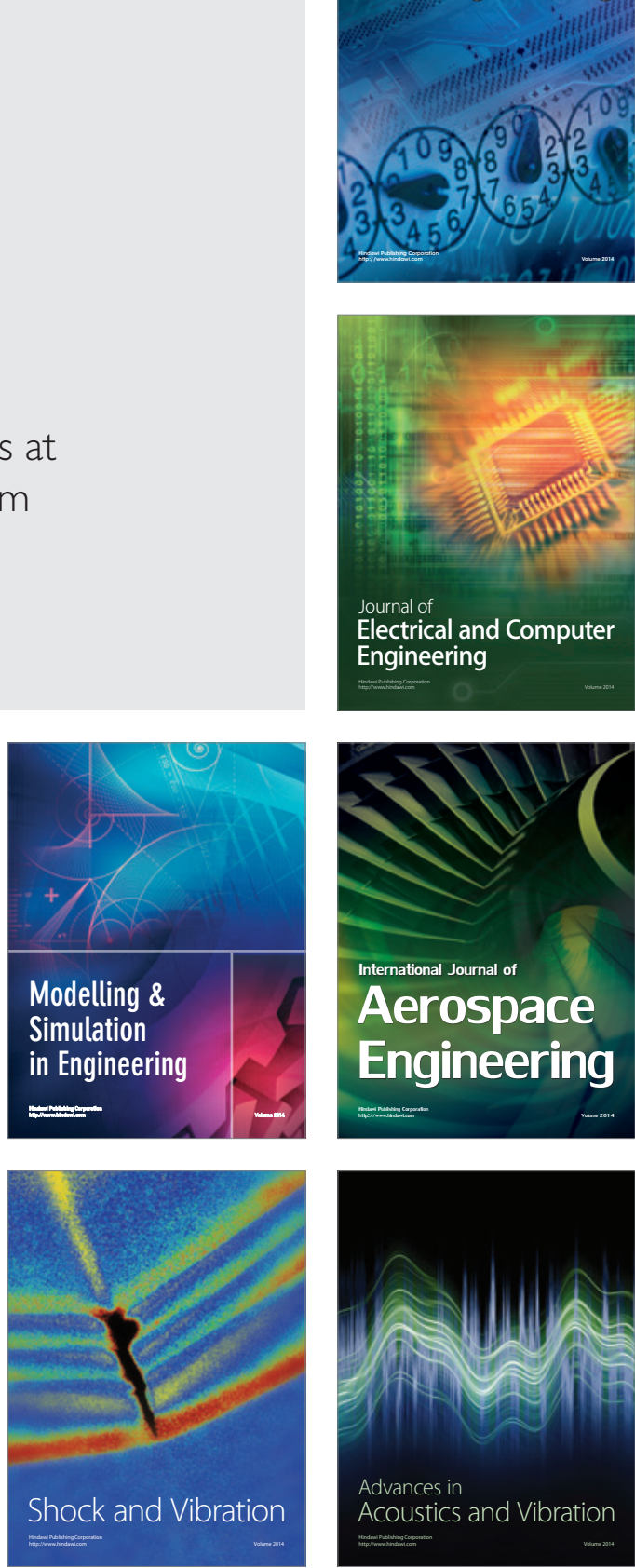